\title{
Building the Canadian Bladder Cancer Research Network (CBCRN): Progress during a pandemic
}

Peter C. Black ${ }^{1}$; Nimira Alimohamed ${ }^{2}$; Wassim Kassouf ${ }^{3}$; John L. Gore ${ }^{4}$; Kathy D. McCoy ${ }^{5}$; Brad H. Nelson ${ }^{6}$; Daniel D. De Carvalho ${ }^{7,8}$; Rodney J. Ouellette ${ }^{9}$; Ferg Devins ${ }^{10}$; Tony Cornacchia $^{10}$; D. Robert Siemens ${ }^{11}$; David M. Berman ${ }^{12}$; Srikala S. Sridhar ${ }^{13}$; Girish Kulkarni ${ }^{14}$; on behalf of the Canadian Bladder Cancer Research Network

${ }^{1}$ Department of Urologic Sciences, University of British Columbia, Vancouver, BC, Canada; ${ }^{2}$ Department of Oncology, Cumming School of Medicine, University of Calgary, Calgary, AB, Canada; ${ }^{3}$ Department of Urology, McGill University Health Centre, Montreal, QC, Canada; ${ }^{4}$ Department of Urology, University of Washington, Seattle, WA, Unites States; ${ }^{5}$ Department of Physiology and Pharmacology, Cumming School of Medicine, University of Calgary, Calgary, AB, Canada; ${ }^{6}$ Deeley Research Centre, BC Cancer, Victoria, BC, Canada; ${ }^{7}$ Princess Margaret Cancer Centre, University Health Network, Toronto, ON, Canada; ${ }^{8}$ Department of Medical Biophysics, University of Toronto, Toronto, ON, Canada; ${ }^{9}$ Atlantic Cancer Research Institute, Moncton, NB, Canada; ${ }^{10} \mathrm{Patient}$ representative, Bladder Cancer Canada; ${ }^{11}$ Department of Urology, Queen's University, Kingston, ON, Canada; ${ }^{12}$ Cancer Research Institute, Queen's University, Kingston, ON, Canada; ${ }^{13}$ Department of Medical Oncology, Princess Margaret Cancer Centre and the University Health Network, University of Toronto, Toronto, ON, Canada; ${ }^{14}$ Department of Surgery (Urology) and Surgical Oncology, Princess Margaret Cancer Centre and the University Health Network, University of Toronto, Toronto, ON, Canada

Funding: Financial support for the Forum was provided by industry partners (Gold sponsors: Bristol Myers Squibb, EMD Serono, and Pfizer; Silver sponsors: Ferring, Janssen, and Merck). This manuscript was based on a transcript of the meeting drafted by a medical writer provided by the CUA.

Cite as: Black PC, Alimohamed N, Kassouf W, et al. Building the Canadian Bladder Cancer Research Network (CBCRN): Progress during a pandemic. Can Urol Assoc J 2022 February 15; Epub ahead of print. http://dx.doi.org/10.5489/cuaj.7810

Published online February 15, 2022

Corresponding author: Dr. Peter C. Black, Vancouver Prostate Centre, Gordon and Leslie Diamond Health Care Centre, University of British Columbia, Vancouver, BC, Canada; peter.black@ubc.ca 


\section{Introduction}

A multidisciplinary group of healthcare professionals and patient advocacy representatives met virtually at the 2021 Canadian Bladder Cancer Forum (Forum) on February 18 and 19, 2021. This meeting focused on the promotion of bladder cancer research in Canada with updates on ongoing Canadian projects and the development of new research initiatives. The Forum followed 10 months after the launch of the Canadian Bladder Cancer Research Network (CBCRN), which convened a virtual translational research forum in April 2020. ${ }^{1}$

The COVID-19 pandemic has wreaked havoc on research initiatives across the spectrum of medical specialties, and bladder cancer in Canada has been no exception. As was revealed at the 2021 Forum, however, the Canadian bladder cancer community has continued to advance its research agenda. The following are highlights of the meeting.

\section{Bladder Cancer Canada update}

Mr. Ferg Devins, Chairman of the Board of Bladder Cancer Canada (BCC) kicked off the Forum with an important message reflecting the resilience of BCC, describing how BCC has continued despite the pandemic to fulfil its three key mandates of supporting patients, increasing awareness and education, and funding research. More than ever, however, BCC is dependent on healthcare providers to connect patients with bladder cancer with $\mathrm{BCC}$ for support and participation in BCC initiatives. Mr. Devins reviewed the avenues through which BCC provides support to the Canadian research community, especially in the form of research grants. BCC provided $\$ 100,000$ in grants in 2021 that were matched by the CUA.

\section{Patient engagement and implementation science}

The opening scientific session focused on patient engagement in bladder cancer research. Dr. John Gore provided an overview of his group's work on patient engagement and patient-centred trial design. Dr. Nimira Alimohamed followed with a discussion of bladder cancer research priorities in Canada.

\section{Patient-centered trial design in the United States}

Dr. Gore described the development of patient-focused research priorities through the creation of the Bladder Cancer Advocacy Network (BCAN) Patient Survey Network in 2014. ${ }^{2}$ Using a modified Delphi process, through two rounds of surveys involving more than 1,000 patients and caregivers, patient priorities for research were established, stratified by stage of disease. These priorities were distributed to a number of research institutes for consideration for their research budgets.

One of the top-rated questions was the comparative effectiveness of treatments (including intravesical therapy, cystectomy or bladder-sparing alternatives to cystectomy) for patients with intermediate- or high-risk non-muscle-invasive bladder cancer (NMIBC) who have recurred after first-line intravesical therapy. This particular topic was prioritized by Patient-Centered Outcomes Research Institute (PCORI), and is currently being investigated by Dr. Gore, Dr. Angela Smith and colleagues in the ongoing study Comparison of Intravesical Therapy and Surgery as 
Treatment Options for Bladder Cancer (CISTO) Study. ${ }^{3}$ CISTO is a pragmatic, multicenter (academic and community settings), observational study where the patients choose their own treatment. It is designed to answer a question that is not feasibly addressed by a randomized trial. The patient-informed study design includes also outcomes prioritized by patients (Table 1).

\section{Bladder cancer research prioritization in Canada}

Dr. Alimohamed reviewed the results of a Canadian survey of research priorities among bladder cancer patients. This survey was initiated as part of the ongoing Canadian bladder cancer quality of care initiative ${ }^{4}$, building on a similar Canadian survey in kidney cancer ${ }^{5}$ and a UK survey in bladder cancer. ${ }^{6}$ Dr. Alimohamed credited the work of Gore and colleagues ${ }^{2}$ as the foundation for the topic list used in the Canadian survey, aiming to validate the results of the US group in Canadian bladder cancer patients.

A link to the Canadian survey was sent by email using the BCC mailing list to bladder cancer patients and caregivers in March 2020 and September 2020. A total of 504 individuals responded, of whom 495 gave consent to participate. Of these, 429 answered at least $80 \%$ of the survey questions. Most of the respondents $(\sim 80 \%)$ were patients and the remainder were caregivers. Respondents had non-muscle invasive bladder cancer (NMIBC) in 65\% of cases, muscle-invasive disease (MIBC) in 28\% and metastatic disease in 5\%.

The results of the Canadian survey were concordant with the U.S. and U.K. experiences. The top five topics for each disease stage are shown in Table 2. Two new themes that emerged were the BCG shortage, including options for treatment, impact on outcomes and mitigation strategies, and shared decision-making, including tools to help patients gain more knowledge about treatment options and side effects.

Dr. Alimohamed went over the next steps in the research prioritization process, namely, to hold a stakeholder meeting to review the results, update the questions and re-evaluate the priorities; to send a second iteration of the survey to Canadian patients; and to disseminate the results. Dr. Alimohamed also reviewed the alignment of patient research priorities with research funding decisions and fund allocation in both the U.S. and Canada. ${ }^{7}$ There is a plan to repeat this analysis at a later date, after the Canadian priorities have been disseminated.

\section{Clinical research collaboration}

The second session of the Forum was designed to stimulate collaborative clinical research through the CBCRN, mimicking a similar session at the 2020 Bladder Cancer Translational Summit. An open invitation was circulated to all bladder cancer researchers before the Forum requesting submission of concepts that would benefit from involvement from other sites across the country. Eleven researchers presented initiatives in development which are summarized in Table 3. Each researcher will follow-up as needed with potential collaborators to complete next steps, which will be facilitated by the CBCRN. 


\section{Translational research}

The second day of the Forum started with a series of four state-of-the-art lectures summarizing recent high impact research outside of the CBCRN that aligns with the four focus areas of research previously identified at the Canadian bladder cancer translational research summit in April 2020: epigenetics, microbiome, liquid biopsy and tumor immunology. ${ }^{1}$

\section{Epigenetic regulation of endogenous retroelements as an emerging vulnerability and therapeutic opportunity in cancer}

Dr. Daniel De Carvalho explained that there are many potential epigenetic alterations that can contribute to cancer hallmarks such as silencing of tumor suppressor genes, disruption of differentiation, increase in stemness and decrease in immunogenicity. ${ }^{8}$ These provide viable therapeutic targets, as exemplified by histone deacetylase [HDAC] inhibitors, DNA methyltransferase inhibitors and other drug candidates in development. The frequent mutations in chromatin modifying genes observed in bladder cancer suggest that it may be particularly amenable to epigenetic targeting.

Dr. De Carvalho focused especially on the mechanism by which epigenetic therapies activate retroelements such as endogenous retroviruses within the human genome, which leads to double-stranded RNA (dsRNA) formation, which then in turn activates pattern recognition receptors (such as MDA5). This viral mimicry process results in the loss of cancer cell fitness and stimulation of innate and adaptive immune responses in the tumor microenvironment. ${ }^{9-20}$ Dr. De Carvalho explained how he and his colleagues are exploring the viral mimicry pathway with the intent of identifying therapeutic targets that would synergize with the viral mimicry response. Some of their work, published in Nature in October $2020,{ }^{20}$ showed that invertedrepeat Alus are the major source of drug-induced immunogenic dsRNA. Furthermore, they found that the ADAR 1 enzyme restricts the viral mimicry response to epigenetic therapy and can block the immune response. They therefore postulated that combining epigenetic therapies with a therapeutic inhibiting ADAR1 represents a promising strategy for cancer treatment. In mouse models, they showed that combining ADAR1 blockade with a DNA demethylating agent (decitabine).

\section{Microbiome and modulation of cancer immunotherapy}

This segment of the program was introduced by Dr. Dirk Lange, one of the CBCRN Microbiome working group heads. Dr. Lange described the existence of the urinary microbiome and stated that, along with the intestinal and vaginal microbiomes, the urinary microbiome may play a key role in mediating local and distal immune responses. This, he explained, makes the microbiome a key area of research focus as a potential influencer of bladder cancer treatment outcomes. Dr. Lange introduced Dr. Kathy McCoy as the keynote speaker for this session. Dr. McCoy began by explaining that the microbiome is known to modulate cancer in a number of different ways, including disease development, progression and treatment. Targeting the microbiome, she 
said, has the potential to modulate cancer progression, cancer-associated comorbidities, responses to therapy and adverse reactions. ${ }^{21}$

She showed how there is conclusive evidence of elements of the gut microbiome influencing responsiveness to checkpoint inhibitor therapies. ${ }^{22-24}$ Researchers have identified a number of bacterial species as being enriched among patients who are responsive to immune checkpoint inhibitor therapies, as well as several others that are enriched among nonresponders. ${ }^{25}$ However, there was considerable heterogeneity involved in the particular bacterial species, with no clear indicator of which species drive changes in treatment responsiveness. Dr. McCoy and colleagues, including Dr. Lukas Mager, have been working for the past several years on identifying particular bacterial species that might be modulated to enhance responsiveness to immune checkpoint inhibitor therapies. ${ }^{26}$ Using a mouse model of colorectal cancer treated with immune checkpoint inhibitors, Dr. McCoy and colleagues identified five tumor-associated bacteria that were only found in treated mice. They then performed a subsequent experiment in which they monocolonized mice with each of these five bacteria (with a germ-free control) and then injected these animals with tumor cells. Once the tumors were palpable, they administered anti-CTLA-4 or anti-PD-1 inhibitor therapy. They found that three of the five bacteria tested (B. pseudolongum, L. johnsoni and Olsenella sp.) had a substantial impact on promoting efficacy of the immune checkpoint inhibitor with significantly reduced tumor size and significantly greater infiltration of CD8 cells into the tumors when these bacteria were present. Of the three bacteria, B. pseudolongum had the greatest impact. In a mouse experiment where only the bacteria were administered (without tumor or treatment), the team found that $B$. pseudolongum was associated with differentiation of Th1 cells in the gut, but no change in effector function. In a subsequent experiment, where checkpoint inhibitor therapy was added along with B. pseudolongum, effector function (local and systemic production of interferon gamma) was also enhanced.

Dr. McCoy then described further research by her team that identified a bacterial-derived metabolite, inosine, that was associated with immune activation in the presence of a costimulatory factor, such as IFN-gamma. The team also discovered that in order to exert beneficial effects, inosine requires the expression of $\mathrm{A} 2{ }_{\mathrm{A}} \mathrm{R}$ receptors on $\mathrm{T}$ cells. Dr. McCoy and colleagues subsequently investigated the effect of B. pseudolongum and inosine in multiple cancer models, including colorectal cancer, melanoma and bladder cancer. They found that B. pseudolongum or inosine were associated with response to immune checkpoint blockade in these models. This represents an important potential avenue of future research in clinical trials to promote response to immune checkpoint inhibitors in patients.

\section{Deciphering and re-engineering the immune response to cancer}

This section of the program was introduced by Dr. Madhuri Koti, head of the Immunotherapy working group of the CBCRN. As Dr. Koti described in her introduction, bladder cancer has been shown to be particularly susceptible to immunomodulation. She introduced Dr. Brad Nelson, whose team is at the forefront of research into the immune response to cancer and the 
development of immunotherapeutic approaches. Although Dr. Nelson's focus is mostly on ovarian cancer, his talk is of interest for all fields of cancer immunotherapy.

Dr. Nelson described how $T$ cells interact with other cells in the body, including recognition and destruction of non-self cells including cancer cells. For $\mathrm{T}$ cells to be able to exert anti-cancer effects, he explained, there are three requirements that need to be met: presence of antigens (for the $\mathrm{T}$ cells to recognize), access of $\mathrm{T}$ cells to the tumor cells, and $\mathrm{T}$ cell activity when in the tumor microenvironment.

He presented immunohistochemical images of tumors, to describe the three major patterns of tumor-infiltrating lymphocytes (TIL) in solid tumors. Those with a high amount of TIL are called "hot" tumors, where T cells and B cells are distributed throughout the epithelium and stroma; those with very few TIL are described as "cold"; and those in between, with TIL only in the stroma, are described as "warm".

Importantly, he showed research in ovarian cancer demonstrating that the majority of patients actually have a mix of these tumor types. ${ }^{27}$ The implication of this finding, Dr. Nelson explained, was that although there are many systemic factors to consider, there are also some very local considerations that may influence the success or failure of any given treatment. For "cold" tumors, access appears to be the main limitation; TILs are not getting into the areas where they need to be, even though there may be ample antigens available. For "hot" tumors, the TILs clearly have access, but there is a lack of antigens and/or activity. The problem with "warm" tumors is less well understood, but there may be both antigen and access issues.

Dr. Nelson showed work done by his group investigating "cold" tumors, which they found to be associated with a stem-cell-like phenotype. ${ }^{28}$ They looked into which immunologically relevant genes were associated with this observed "stemness". One gene that they identified as being associated with cold tumor types across a number of different cancers was the PVD/CD155 gene. CD155, Dr. Nelson explained, is a ligand expressed by many different tumor cell types, which binds to the T cell immunoglobulin and ITIM domain (TIGIT) on $\mathrm{T}$ cells and NK cells. While the CD155 pathway operates similarly to - and in parallel withthe PD-1/PD-L1 pathway, ${ }^{29} \mathrm{CD} 155$ is more prevalent in the "cold" tumor types than in "hot" tumors, while PD-L1 is the opposite. ${ }^{30}$ This complementary expression pattern led to the concept of combination inhibition of the PD-1/PD-L1 and CD155/TIGIT pathways, which has been a focus of research for a number of different groups who have ongoing trials investigating such combinations. ${ }^{29}$

With respect to the "hot" tumor type, research that Dr. Nelson's group was involved with showed that the majority of TILs in the tumor microenvironment are bystanders, and do not recognize the antigens. ${ }^{31}$ This has led researchers to try to determine which TILs are genuinely tumor-reactive. Dr. Nelson explained that several different groups have identified co-expression of CD39, PD-1 and CD103 is associated with tumor-reactive and strongly prognostic CD8 TIL. ${ }^{32}$ In terms of prognosis, Dr. Nelson discussed work that he was involved with showing that "hot" tumor cells harboring both CD8 T cells and B cells are associated with better overall survival 
than those with only CD8 T cells, which in turn are associated with better survival than those with neither. ${ }^{33}$ Several other groups have also reported that the presence of B cells enhances response to immune checkpoint inhibitor therapy in sarcoma and melanoma. ${ }^{34-36}$

Dr. Nelson discussed how these findings provide a pathway forward for research into new therapeutics to improve immune response across a variety of cancers.

\section{Capture of extracellular vesicles: A liquid biopsy source of multi-omic information for patient monitoring}

The final translational research presentation was introduced by Dr. Paul Toren, one of the coleads of the CBCRN's Biomarkers working group. Dr. Toren reminded the participants that biomarkers have been identified as a key research priority not only by the CBCRN, but also by bladder cancer patients, as described above by Drs. Gore and Alimohamed. Dr. Toren introduced Dr. Rodney Ouellette as the keynote speaker for this session.

Dr. Ouellette's talk focused on a technology that his group has been developing that allows the capture of novel, important information from liquid biopsy. He emphasized at the start of his presentation that one of the key advantages of liquid biopsy compared to standard biopsy is the ability to acquire longitudinal samples during the course of a patient's disease. Liquid biopsy can be performed on a number of bodily fluids. The focus of Dr. Ouellette's research, extracellular vesicles (EVs: exosomes and microvesicles), can be found in all bodily fluids and his team has been able to harvest these from all liquid sources they have investigated. The key advantages to analyzing EVs are that they are more abundant compared to circulating tumor cells, they contain more biological information compared to cell-free (cf)DNA or cfRNA and they are potentially useful in the clinical setting.

Dr. Ouellette described a peptide, Vn96, that was identified serendipitously as being able to capture EVs from biologic fluids. After making this observation, Dr. Ouellette's team developed a protocol whereby a single plasma sample of 1 to $4 \mathrm{~mL}$ could be used to capture enough material for downstream analysis (e.g., by next-generation sequencing, polymerase chain reaction and/or mass spectrometry). In the process of the development of this protocol, Dr. Ouellette's team also discovered that the use of the Vn96 peptide was associated with harvesting an abundance of cfDNA.

Using both EV and cfDNA, the team developed assays that can provide meaningful clinical information, particularly captured longitudinally. For example, EV counts and flow cytometry, nucleic acid concentration, DNA mutation and fusion gene status can all provide information about tumor burden and residual disease. Quantifying DNA methylation, as well as RNA transcriptomic analysis, protein analysis, lipidomics and metabolomics can all provide information about dynamic cell processes.

Dr. Ouellette then discussed research from his team about the practical use of liquid biopsy in lung cancer. They found that using fluid from bronchial lavage, they were able to identify the presence of driver mutations that would help the clinician initiate appropriate targeted therapy in a timely manner, without needing to wait for tissue biopsy. 
Also in the lung cancer field, potential uses for EV/cfDNA analyses from liquid biopsy could be to analyze post-operative samples to determine whether resection was completely successful or if there is residual disease, which would help direct the course of therapy in the adjuvant setting. Additionally, Dr. Ouellette's team investigated the possibility of liquid biopsy being able to identify subgroups of patients that are more likely to respond to particular therapies. They found that among patients with non-small-cell lung cancer treated with pembrolizumab (who all had high expression of PD-L1), there was a marked difference in pretreatment RNA expression profiles between those who responded and those who did not respond to pembrolizumab treatment.

Dr. Ouellette showing a list of some of the promising research initiatives that have used the EV liquid biopsy technology in various cancers, including prostate, lung, glioblastoma and melanoma, as well as in non-cancer settings (e.g., amyotrophic lateral sclerosis [ALS]). ${ }^{37-42}$

\section{Bladder cancer quality of care \& Canadian Bladder Cancer Information System (CBCIS)}

The final session of the Forum involved two related talks by Drs. Wassim Kassouf and Rob Siemens. Dr. Kassouf provided an update on the Canadian Bladder Cancer Information System (CBCIS), including a report on quality indicators captured within the system. Dr. Siemens wrapped up the session with a report on the ongoing Canadian benchmarking exercise in bladder cancer.

\section{CBCIS and quality indicators: An update}

The CBCIS is a not-for-profit joint venture between BCC and the Research Institute of McGill University Health Centre. Dr. Kassouf explained that the database was developed to collect upto-date, anonymous information about all aspects of the care of patients with high grade bladder cancer across Canada. He showed that there were 5,436 patients enrolled in the CBCIS from 14 sites. He also showed some of the characteristics of the patients enrolled, highlighting that there is a good distribution of patients across disease stages (NMIBC, MIBC and metastatic).

Dr. Kassouf then reviewed the development of the bladder cancer quality indicators, which was a multi-step process involving a modified Delphi approach and a large multidisciplinary committee. ${ }^{4,43-45}$ The indicators covered all aspects of care, including multiple indicators for diagnosis, staging, treatment, prophylaxis, organizational processes and follow-up. The group identified 13 critical indicators and established benchmark targets for each of these variables. ${ }^{4}$ Dr. Kassouf explained that the CBCIS captures information on nine of these 13 indicators. $\mathrm{He}$ provided a summary of these nine indicators, as well as several other indicators of potential clinical interest (Table 4). While some of the benchmarks had been met in the CBCIS dataset, there is still considerable room for improvement in other indicators.

\section{Report on Canadian benchmarking exercise in bladder cancer}

Dr. Siemens discussed benchmarking in the context of bladder cancer care. He discussed how quality indicators and benchmarking can be used to develop a "scorecard" that can track performance over time. He showed an example of such a scorecard for the care of patients with 
NMIBC that he developed for his own use based on the indicators and benchmarks discussed above. The scorecard included the benchmark, baseline performance, the performance at the time of the last report and the performance for the current six-month cycle.

Dr. Siemens discussed the challenges involved in implementing and using scorecards, such as the difficulty in obtaining high-quality data, and the need to strategically limit the scope of the measures being evaluated. He highlighted the importance of being flexible in choosing performance measures, as the chosen measures should reflect the critical performance issues of the day - and these may change over time.

With respect to benchmarking for quality indicators, one must also consider that there is real variation, even after case mix and other adjustments are made between hospitals and providers. Dr. Siemens described several methods that can be used to set benchmarks. A combination of evidence-based analysis and expert opinion was the method used for the quality indicators described above. ${ }^{4,44,45}$ Others have simply used the median for the given variable as the benchmark. Some use objective, reproducible approaches, including Criterion-based Benchmarking (CBB), which seeks to control for barriers to access, ${ }^{46}$ and the University of Alabama at Birmingham's Achievable Benchmarks of Care (ABC), which bases benchmarks on the top performers. ${ }^{47}$

The different methodologies for benchmarking have been compared in a Canadian bladder cancer setting. Dr. Siemens reviewed a paper that evaluated different benchmarking strategies in the context of perioperative chemotherapy utilization for MIBC..$^{48}$ Using the Ontario Cancer Registry from 2004 to 2013, they found that perioperative chemotherapy was administered to $31 \%$ of patients, with a range across institutions of $0-52 \%$. Using the CBB method, the estimated benchmark was set somewhat higher, at 36\% (representing a relative shortfall of $14 \%$ in Ontario), while the ABC method identified an optimal benchmark of $45 \%$ (representing a $31 \%$ relative shortfall).

Dr. Siemens presented some approximately 2000 patients who received cystectomy for MIBC in Ontario up to 2015, comparing the actual performance with the Canadian benchmarks described above. The results, shown in Table 5, revealed major shortcomings across the indicators.

Looking more closely at some of these indicators, Dr. Siemens used the median, CBB and $\mathrm{ABC}$ methods to redefine benchmarks. For the wait time from TURBT to cystectomy, for example, the Canadian group defined the benchmark as $90 \%$ of patients proceeding to cystectomy within six weeks of TURBT, but the actual median time in Ontario data was 9.14 weeks. The ABC criteria showed that only 54\% of patients had their cystectomy within six weeks even among the top performers. Dr. Siemens speculated that the six-week timeframe and/or the $90 \%$ threshold for benchmarking was too optimistic.

\section{Conclusions}

The bladder cancer research and clinical care communities continue to thrive despite the limitations of the COVID-19 pandemic. Patient care is improving through high quality clinical 
trials and rigorous translational research that is rapidly advancing our understanding of the disease. Collaboration of bladder cancer researchers through the fledgling CBCRN will build on current strengths in the Canadian research environment and leverage these strengths in new partnerships with researchers in related research fields. The CBCRN promises to accelerate progress in bladder cancer research across the country.

\section{Acknowledgement}

This study was supported by the Institute for Clinical Evaluative Sciences (ICES), which is funded by an annual grant from the Ontario Ministry of Health and Long-Term Care (MOHLTC). Parts of this material are based on data and information compiled and provided by CIHI. The opinions, results, and conclusions reported in this paper are those of the authors and are independent from the funding sources and CIHI. No endorsement by ICES or the Ontario MOHLTC is intended or should be inferred. Parts of this material are based on data and information provided by Ontario Health $(\mathrm{OH})$. The opinions, results, view, and conclusions reported in this paper are those of the authors and do not necessarily reflect those of $\mathrm{OH}$. No endorsement by $\mathrm{OH}$ is intended or should be inferred. Dr. Siemens had full access to all the ICES data in the study and takes responsibility for the integrity of the data and the accuracy of the data analysis. 


\section{References}

1. Koti M, Berman DM, Siemens DR, et al. Building a Canadian Translational Bladder Cancer Research Network. Can Urol Assoc J 2020;14:E475-81.

2. Smith AB, Chisolm S, Deal A, et al. Patient-centered prioritization of bladder cancer research. Cancer 2018;124:3136-44.

3. Clinicaltrials.gov. Comparison of Intravesical Therapy and Surgery as Treatment Options for Bladder Cancer (CISTO). ClinicalTrials.gov Identifier: NCT03933826.

4. Kassouf W, Aprikian A, Saad F, et al. Continuing towards optimization of bladder cancer care in Canada: Summary of the third Bladder Cancer Canada-Canadian Urological Association-Canadian Urologic Oncology Group (BCC-CUA-CUOG) bladder cancer quality of care consensus meeting. Can Urol Assoc J 2020;14:E115-25.

5. Jones J, Bhatt J, Avery J, et al. The kidney cancer research priority-setting partnership: Identifying the top 10 research priorities as defined by patients, caregivers, and expert clinicians. Can Urol Assoc J 2017;11:379-87.

6. Bessa A, Maclennan S, Enting D, et al. Consensus in Bladder Cancer Research Priorities Between Patients and Healthcare Professionals Using a Four-stage Modified Delphi Method. Eur Urol 2019;76:258-59.

7. Kaiser J, Litt I, Smith AB, et al. Bladder cancer research funding in Canada and the United States: A comparison between stakeholder priorities and resource allocation from 2017 to 2019 [abstract]. J Clin Oncol 2021;39:422.

8. Feng S, De Carvalho DD. Clinical advances in targeting epigenetics for cancer therapy. FEBS J. Epub $2021 \mathrm{Feb} 5$.

9. Loo Yau H, Ettayebi I, De Carvalho DD. The Cancer Epigenome: Exploiting Its Vulnerabilities for Immunotherapy. Trends Cell Biol 2019;29:31-43.

10. Roulois D, Loo Yau H, Singhania R, et al. DNA-Demethylating Agents Target Colorectal Cancer Cells by Inducing Viral Mimicry by Endogenous Transcripts. Cell 2015;162:961-73.

11. Chiappinelli KB, Strissel PL, Desrichard A, et al. Inhibiting DNA Methylation Causes an Interferon Response in Cancer via dsRNA Including Endogenous Retroviruses. Cell 2015;162:974-986.

12. Brocks D, Schmidt CR, Daskalakis M, et al. DNMT and HDAC inhibitors induce cryptic transcription start sites encoded in long terminal repeats. Nat Genet 2017;49:1052-1060.

13. Goel S, DeCristo MJ, Watt AC, et al. CDK4/6 inhibition triggers anti-tumour immunity. Nature 2017;548:471-75.

14. Zhang H, Pandey S, Travers M, et al. Targeting CDK9 Reactivates Epigenetically Silenced Genes in Cancer. Cell 2018;175:1244-58 e1226.

15. Canadas I, Thummalapalli R, Kim JW, et al. Tumor innate immunity primed by specific interferon-stimulated endogenous retroviruses. Nat Med 2018;24:1143-50.

16. Hirukawa A, Singh S, Wang J, et al. Reduction of Global H3K27me(3) Enhances HER2/ErbB2 Targeted Therapy. Cell Rep 2019;29:249-57 e248. 
17. Krug B, De Jay N, Harutyunyan AS, et al. Pervasive H3K27 Acetylation Leads to ERV Expression and a Therapeutic Vulnerability in H3K27M Gliomas. Cancer Cell 2019;35:782-97 e788.

18. Leruste A, Tosello J, Ramos RN, et al. Clonally Expanded T Cells Reveal Immunogenicity of Rhabdoid Tumors. Cancer Cell 2019;36:597-612 e598.

19. Deblois G, Tonekaboni SAM, Grillo G, et al. Epigenetic Switch-Induced Viral Mimicry Evasion in Chemotherapy-Resistant Breast Cancer. Cancer Discov 2020;10:1312-1329.

20. Mehdipour P, Marhon SA, Ettayebi I, et al. Epigenetic therapy induces transcription of inverted SINEs and ADAR1 dependency. Nature 2020;588:169-173.

21. Dzutsev A, Badger JH, Perez-Chanona E, et al. Microbes and Cancer. Annu Rev Immunol 2017;35:199-228.

22. Routy B, Le Chatelier E, Derosa L, et al. Gut microbiome influences efficacy of PD-1based immunotherapy against epithelial tumors. Science 2018;359:91-97.

23. Gopalakrishnan V, Spencer CN, Nezi L, et al. Gut microbiome modulates response to anti-PD-1 immunotherapy in melanoma patients. Science 2018;359:97-103.

24. Matson V, Fessler J, Bao R, et al. The commensal microbiome is associated with antiPD-1 efficacy in metastatic melanoma patients. Science 2018;359:104-08.

25. Helmink BA, Khan MAW, Hermann A, Gopalakrishnan V, Wargo JA. The microbiome, cancer, and cancer therapy. Nat Med 2019;25:377-88.

26. Miao KC, Blanton JP, Anderson CP, et al. Universal coherence protection in a solidstate spin qubit. Science 2020;369:1493-97.

27. Zhang AW, McPherson A, Milne K, et al. Interfaces of Malignant and Immunologic Clonal Dynamics in Ovarian Cancer. Cell 2018;173:1755-69 e1722.

28. Miranda A, Hamilton PT, Zhang AW, et al. Cancer stemness, intratumoral heterogeneity, and immune response across cancers. Proc Natl Acad Sci U S A 2019;116:9020-29.

29. Chauvin JM, Zarour HM. TIGIT in cancer immunotherapy. J Immunother Cancer 2020;8:e000957.

30. Smazynski J, Hamilton PT, Thornton S, et al. The immune suppressive factors CD155 and PD-L1 show contrasting expression patterns and immune correlates in ovarian and other cancers. Gynecol Oncol 2020;158:167-77.

31. Scheper W, Kelderman S, Fanchi LF, et al. Low and variable tumor reactivity of the intratumoral TCR repertoire in human cancers. Nat Med 2019;25:89-94.

32. Laumont CM, Wouters MCA, Smazynski J, et al. Single-cell Profiles and Prognostic Impact of Tumor-Infiltrating Lymphocytes Coexpressing CD39, CD103, and PD-1 in Ovarian Cancer. Clin Cancer Res 2021;27:4089-100.

33. Nielsen JS, Sahota RA, Milne K, et al. CD20+ tumor-infiltrating lymphocytes have an atypical CD27- memory phenotype and together with CD8+ T cells promote favorable prognosis in ovarian cancer. Clin Cancer Res 2012;18:3281-92.

34. Petitprez F, de Reynies A, Keung EZ, et al. B cells are associated with survival and immunotherapy response in sarcoma. Nature 2020;577:556-60.

35. Helmink BA, Reddy SM, Gao J, et al. B cells and tertiary lymphoid structures promote immunotherapy response. Nature 2020;577:549-55. 
36. Cabrita R, Lauss M, Sanna A, et al. Tertiary lymphoid structures improve immunotherapy and survival in melanoma. Nature 2020;577:561-65.

37. Davey M, Benzina S, Savoie M, Breault G, Ghosh A, Ouellette RJ. Affinity Captured Urinary Extracellular Vesicles Provide mRNA and miRNA Biomarkers for Improved Accuracy of Prostate Cancer Detection: A Pilot Study. Int J Mol Sci 2020;21: 8330.

38. Foroni C, Zarovni N, Bianciardi L, et al. When Less Is More: Specific Capture and Analysis of Tumor Exosomes in Plasma Increases the Sensitivity of Liquid Biopsy for Comprehensive Detection of Multiple Androgen Receptor Phenotypes in Advanced Prostate Cancer Patients. Biomedicines 2020;8:131.

39. Taylor C, Chacko S, Davey M, et al. Peptide-Affinity Precipitation of Extracellular Vesicles and Cell-Free DNA Improves Sequencing Performance for the Detection of Pathogenic Mutations in Lung Cancer Patient Plasma. Int J Mol Sci 2020;21:9083.

40. Bijnsdorp IV, Schelfhorst T, Luinenburg M, et al. Feasibility of phosphoproteomics to uncover oncogenic signalling in secreted extracellular vesicles using glioblastomaEGFRVIII cells as a model. J Proteomics 2021;232:104076.

41. Zocco D, Bernardi S, Novelli M, et al. Isolation of extracellular vesicles improves the detection of mutant DNA from plasma of metastatic melanoma patients. Sci Rep 2020;10:15745.

42. Saucier D, Wajnberg G, Roy J, et al. Identification of a circulating miRNA signature in extracellular vesicles collected from amyotrophic lateral sclerosis patients. Brain Res 2019;1708:100-108.

43. Kassouf W, Aprikian A, Black P, et al. Recommendations for the improvement of bladder cancer quality of care in Canada: A consensus document reviewed and endorsed by Bladder Cancer Canada (BCC), Canadian Urologic Oncology Group (CUOG), and Canadian Urological Association (CUA), December 2015. Can Urol Assoc J 2016;10:E46-80.

44. Khare SR, Aprikian A, Black P, et al. Quality indicators in the management of bladder cancer: A modified Delphi study. Urol Oncol 2017;35:328-34.

45. Kassouf W, Aprikian A, Saad F, et al. Improving patient journey and quality of care: Summary from the second Bladder Cancer Canada-Canadian Urological AssociationCanadian Urologic Oncology Group (BCC-CUA-CUOG) bladder cancer quality of care consensus meeting. Can Urol Assoc J 2018;12:E281-97.

46. Barton MB, Gabriel GS, Delaney GP. Testing criterion-based benchmarking for the appropriate use of radiotherapy. Radiother Oncol 2018;128:406-10.

47. Weissman NW, Allison JJ, Kiefe CI, et al. Achievable benchmarks of care: the ABCs of benchmarking. J Eval Clin Pract 1999;5:269-81.

48. Karim S, Mackillop WJ, Brennan K, et al. Estimating the optimal perioperative chemotherapy utilization rate for muscle-invasive bladder cancer. Cancer Med 2019;8:6258-71. 
Figures and Tables

\begin{tabular}{|c|c|}
\hline \multicolumn{2}{|c|}{$\begin{array}{l}\text { Table 1. Outcomes being investigated in the ongoing CISTO } \\
\text { trial (radical cystectomy vs. bladder-sparing therapy for } \\
\text { NMIBC after failure of first-line BCG) }\end{array}$} \\
\hline \multicolumn{2}{|c|}{ Outcomes } \\
\hline Primary & Health-related quality of life \\
\hline Secondary & $\begin{array}{l}\text { Urinary and sexual function } \\
\text { Treatment preferences } \\
\text { Decision regret } \\
\text { Financial toxicity } \\
\text { Healthcare utilization } \\
\text { Bladder-cancer specific survival } \\
\text { Progression to muscle-invasive bladder cancer }\end{array}$ \\
\hline
\end{tabular}

BCG: bacillus Calmette-Guerin; NMIBC: non-muscle-invasive bladder cancer.

\begin{tabular}{|c|c|c|c|}
\hline $\begin{array}{l}\text { Topic } \\
\text { rank }\end{array}$ & NMIBC & MIBC & Metastatic disease \\
\hline 1 & $\begin{array}{l}\text { Biomarkers for treatment } \\
\text { response }\end{array}$ & $\begin{array}{l}\text { Improving education on } \\
\text { understanding prognosis }\end{array}$ & $\begin{array}{l}\text { Educating patients on } \\
\text { prognosis }\end{array}$ \\
\hline 2 & $\begin{array}{l}\text { Effect of diet/lifestyle/nutrition } \\
\text { on incidence, severity, } \\
\text { treatment success }\end{array}$ & $\begin{array}{l}\text { Effect of diet/lifestyle/nutrition } \\
\text { on incidence, severity, } \\
\text { treatment success }\end{array}$ & $\begin{array}{l}\text { Sequence of } \\
\text { treatments } \\
\text { for metastatic disease }\end{array}$ \\
\hline 3 & Optimal surveillance protocols & $\begin{array}{l}\text { Patient selection for } \\
\text { neoadjuvant chemotherapy }\end{array}$ & Caregiver support \\
\hline 4 & $\begin{array}{l}\text { Pain reduction with cystoscopy } \\
\text { and intravesical treatment }\end{array}$ & $\begin{array}{l}\text { Improving education about } \\
\text { post-surgery expectations }\end{array}$ & $\begin{array}{l}\text { Cost effectiveness of } \\
\text { new treatments }\end{array}$ \\
\hline 5 & $\begin{array}{l}\text { Managing depression and } \\
\text { anxiety in bladder cancer } \\
\text { patients }\end{array}$ & $\begin{array}{l}\text { Treatment for sexual } \\
\text { rehabilitation }\end{array}$ & NA \\
\hline
\end{tabular}

MIBC: muscle-invasive bladder cancer; NMIBC: non-muscle-invasive bladder cancer. 


\begin{tabular}{|c|c|c|}
\hline Presenter & Institution & Project title \\
\hline $\begin{array}{l}\text { Louise } \\
\text { McLoughlin/ } \\
\text { Girish Kulkarni }\end{array}$ & $\begin{array}{l}\text { University of } \\
\text { Toronto }\end{array}$ & $\begin{array}{l}\text { Artificial intelligence in the diagnosis and staging of } \\
\text { upper tract urothelial carcinoma. }\end{array}$ \\
\hline Luke Lavallée & University of Ottawa & $\begin{array}{l}\text { Randomized controlled trial of venous thromboembolic } \\
\text { event prophylaxis in patients undergoing neoadjuvant } \\
\text { chemotherapy for muscle invasive bladder cancer. }\end{array}$ \\
\hline Paul Toren & Laval University & $\begin{array}{l}\text { 5-alpha reductase inhibitors in the secondary } \\
\text { prevention of low-risk non-muscle invasive bladder } \\
\text { cancer. }\end{array}$ \\
\hline Wassim Kassouf & McGill University & $\begin{array}{l}\text { Randomized controlled trial of immunotherapy versus } \\
\text { immunotherapy plus an immunogenic dose of } \\
\text { radiotherapy for BCG-unresponsive non-muscle } \\
\text { invasive bladder cancer. }\end{array}$ \\
\hline Vincent Fradet & Laval University & $\begin{array}{l}\text { Impact of lifestyle factors in localized and metastatic } \\
\text { bladder cancer. }\end{array}$ \\
\hline Alex Zlotta & $\begin{array}{l}\text { University of } \\
\text { Toronto }\end{array}$ & $\begin{array}{l}\text { Randomized controlled trial of two different BCG } \\
\text { strains. }\end{array}$ \\
\hline $\begin{array}{l}\text { Carlos Stecca/ } \\
\text { Srikala Sridhar }\end{array}$ & $\begin{array}{l}\text { University of } \\
\text { Toronto }\end{array}$ & $\begin{array}{l}\text { A phase II study of lurbinectedin in metastatic small } \\
\text { cell carcinoma of the genitourinary tract in patients } \\
\text { unfit for or who have progressed to platinum-based } \\
\text { chemotherapy. }\end{array}$ \\
\hline Aly-Khan Lalani & $\begin{array}{l}\text { McMaster } \\
\text { University }\end{array}$ & $\begin{array}{l}\text { Trial in rare genitourinary malignancies (including } \\
\text { non-urothelial). }\end{array}$ \\
\hline $\begin{array}{l}\text { Ryan McLarty/ } \\
\text { Rodney Breau }\end{array}$ & University of Ottawa & $\begin{array}{l}\text { Development of a radical cystectomy procedural } \\
\text { guideline. }\end{array}$ \\
\hline Ahmed Kotb & $\begin{array}{l}\text { Northern Ontario } \\
\text { School of Medicine }\end{array}$ & $\begin{array}{l}\text { Association of intravesical BCG and risk of COVID-19 } \\
\text { infection. }\end{array}$ \\
\hline $\begin{array}{l}\text { Franciso } \\
\text { Vera-Badillo }\end{array}$ & Queens University & $\begin{array}{l}\text { Impact of neutrophil-to-lymphocyte ratio on metastatic } \\
\text { urothelial cancer patients receiving } 2^{\text {nd- }}-1 \text { ine } \\
\text { immunotherapy: retrospective and prospective study. }\end{array}$ \\
\hline
\end{tabular}




\begin{tabular}{|c|c|c|}
\hline Indicator & Benchmark & $\begin{array}{l}\text { Current } \\
\text { status }\end{array}$ \\
\hline \multicolumn{3}{|l|}{ Quality indicators with benchmarks } \\
\hline $\begin{array}{l}\text { Percent of patients with TURBT completed }<3 \text { weeks after } \\
\text { cystoscopy }\end{array}$ & $>80 \%$ & $42 \%$ \\
\hline $\begin{array}{l}\text { Percent of patients with no neoadjuvant chemotherapy who had } \\
\text { radical cystectomy within six weeks of last TURBT }\end{array}$ & $>90 \%$ & $17 \%$ \\
\hline $\begin{array}{l}\text { For patients with high-risk NMIBC, percent who had intravesical } \\
\text { BCG induction course with at least one year of maintenance }\end{array}$ & $>70 \%$ & $77 \%$ \\
\hline $\begin{array}{l}\text { For patients with MIBC, percent who received any curative-intent } \\
\text { definitive therapy (radical cystectomy or radiation-based therapy) }\end{array}$ & $>80 \%$ & $67 \%$ \\
\hline $\begin{array}{l}\text { Percent of patients with adequate lymph node dissection defined as } \\
>14 \text { nodes }\end{array}$ & $>85 \%$ & $72 \%$ \\
\hline $\begin{array}{l}\text { For patients with MIBC and receiving neoadjuvant chemotherapy, } \\
\text { percent who completed a minimum of three cycles of cisplatin- } \\
\text { based combination therapy }\end{array}$ & $>80 \%$ & $48 \%$ \\
\hline $\begin{array}{l}\text { Percent of metastatic patients receiving second-line systemic } \\
\text { therapy after receiving first-line systemic therapy }\end{array}$ & $>70 \%$ & $47 \%$ \\
\hline Percent with positive soft tissue margin at radical cystectomy & $<10 \%$ & $14 \%$ \\
\hline Percent of patients deceased within 90 days post-cystectomy & $<5 \%$ & $4.5 \%$ \\
\hline \multicolumn{3}{|l|}{ Quality indicators without benchmarks } \\
\hline \multicolumn{2}{|l|}{ Percent of TURBT with muscle in the specimen } & $62 \%$ \\
\hline \multicolumn{2}{|l|}{ Percent of T1 with muscle on TURBT } & $60 \%$ \\
\hline \multicolumn{2}{|l|}{ Percent of T1 undergoing re-TURBT ( $<90$ days) } & $17 \%$ \\
\hline \multicolumn{2}{|l|}{ Percent of HR-NMIBC receiving induction BCG } & $40 \%$ \\
\hline \multicolumn{2}{|c|}{ Percent with 1-year recurrence of TaHG } & $31 \%$ \\
\hline \multicolumn{2}{|c|}{ Percent receiving neoadjuvant chemotherapy prior to radical cystectomy for MIBC } & $43 \%$ \\
\hline \multicolumn{2}{|c|}{ Percent of MIBC patients receiving radical radiotherapy } & $10 \%$ \\
\hline \multicolumn{2}{|l|}{ Percent of greater than $\mathrm{pT} 3+$ or $\mathrm{N}+$ receiving adjuvant chemotherapy } & $6 \%$ \\
\hline \multicolumn{2}{|l|}{ Percent of patients receiving concurrent chemotherapy } & $78 \%$ \\
\hline \multicolumn{2}{|c|}{$\begin{array}{l}\text { Percent of patients who receive chemoradiation for bladder cancer who undergo } \\
\text { neoadjuvant chemotherapy }\end{array}$} & $37 \%$ \\
\hline
\end{tabular}

BCG: bacillus Calmette-Guerin; MIBC: muscle-invasive bladder cancer; NMIBC: non-muscleinvasive bladder cancer; TURBT: transurethral resection of a bladder tumor. 


\begin{tabular}{|l|l|l|l|}
\hline Table 5. Status of key quality-of-care indicators for MIBC in Ontario \\
\hline Indicator & Benchmark & $\begin{array}{l}\text { Percent of } \\
\text { institutions } \\
\text { meeting } \\
\text { benchmark }\end{array}$ & $\begin{array}{l}\text { Percent of } \\
\text { patients } \\
\text { meeting } \\
\text { benchmark }\end{array}$ \\
\hline 90-day mortality & $<5 \%$ & $37 \%$ & $31 \%$ \\
\hline $\begin{array}{l}\text { Percent of patients with adequate lymph } \\
\text { node dissection defined as }>14 \text { nodes }\end{array}$ & $>85 \%$ & 0 & 0 \\
\hline $\begin{array}{l}\text { Percent with positive soft tissue margin } \\
\text { at radical cystectomy }\end{array}$ & $<10 \%$ & $46 \%$ & $48 \%$ \\
\hline $\begin{array}{l}\text { Percent of patients with MIBC being } \\
\text { seen by medical oncologist (or discussed } \\
\text { at a multidisciplinary tumor board) } \\
\text { preoperatively for consideration of } \\
\text { neoadjuvant chemotherapy }\end{array}$ & $>90 \%$ & $2 \%$ & $0.5 \%$ \\
\hline $\begin{array}{l}\text { Percent of patients with MIBC on } \\
\text { TURBT being referred to radiation } \\
\text { oncology preoperatively for } \\
\text { consideration of radiotherapy }\end{array}$ & $>50 \%$ & 0 & 0 \\
\hline Annual surgeon volume & $>90 \%$ & 0 & $50 \%$ \\
\hline $\begin{array}{l}\text { Percent of patients with no neoadjuvant } \\
\text { chemotherapy who had radical } \\
\text { cystectomy within six weeks of last } \\
\text { TURBT }\end{array}$ & $>6$ & $20 \%$ & \\
\hline MIBC: muscle-invasive bladder cancer; & & & \\
\hline
\end{tabular}

MIBC: muscle-invasive bladder cancer; TURBT: transurethral resection of a bladder tumor. 